\title{
DIGITAL MUSEUMIFICATION AS A PROMISING MECHANISM FOR THE PRESERVATION AND PRESENTATION (REPRESENTATION) OF HISTORICAL AND CULTURAL HERITAGE: TOWARDS THE FORMULATION OF THE QUESTION ${ }^{1}$
}

\author{
Vladimir A. Zolotovskiy \\ Volgograd State University, Volgograd, Russian Federation
}

\begin{abstract}
Introduction. During the $20^{\text {th }}$ century the functions and essence of museums have undergone changes. One of the most relevant functions of modern museums is museumification. The purpose of the paper is to reveal the features of digital museumification as a promising direction and an actual form of museumification of material and non-material objects included in the socio-cultural environment. Discussion. The undertaken historiographical review allowed us to conclude that there is a sufficient methodological and factual basis for a comprehensive study of the essence of museumification. At the same time, many problems of the theory and practice of museumification have not even received a problematic definition. Analysis. Museumification is of particular importance in the activities of saving, preserving, and introducing cultural heritage objects into the modern socio-cultural environment. In modern domestic and foreign practice museumification develops in two main directions: removal from the natural area and museumification of cultural heritage monuments through actualization or introduction into the socio-cultural environment. The monument, which is a harmonious part of the socio-cultural environment, does not require artificial conservation of the habitat or the area of the monument. It is determined that for such objects of museumification it is reasonable to use the concept of "dynamic museumification". The most adequate form of "dynamic museumification" should be considered digital museumification. Results. Digital museumification should be understood as an activity for the transformation of cultural heritage objects into living objects that develop together with their cultural space and socio-cultural environment. Digital museumification is presented as a combination of actions and means pointed at ensuring the implementation of preservation and popularizations tasks within the framework of the "smart city" system being formed. Digital museumification objectively makes it necessary to create open information bases for all interested persons. The detected connection between the space of a monument and the channels of forming the historical memory determines the need for organizing digital museumification in a digital creative urban space.

Key words: museumification, popularization of cultural heritage objects, cultural heritage objects, historical memory, creative space.

Citation. Zolotovskiy V.A. Digital Museumification As a Promising Mechanism for the Preservation and Presentation (Representation) of Historical and Cultural Heritage: Towards the Formulation of the Question. Vestnik Volgogradskogo gosudarstvennogo universiteta. Seriya 4. Istoriya. Regionovedenie. Mezhdunarodnye otnosheniya [Science Journal of Volgograd State University. History. Area Studies. International Relations], 2021, vol. 26, no. 5, pp. 256-271. (in Russian). DOI: https://doi.org/10.15688/jvolsu4.2021.5.21
\end{abstract}

\section{ЦИФРОВАЯ МУЗЕЕФИКАЦИЯ КАК ПЕРСПЕКТИВНЫЙ МЕХАНИЗМ СОХРАНЕНИЯ И ПРЕЗЕНТАЦИИ (РЕПРЕЗЕНТАЦИИ) ИСТОРИКО-КУЛЬТУРНОГО НАСЛЕДИЯ: К ПОСТАНОВКЕ ВОПРОСА ${ }^{1}$}

\author{
Владимир Алексеевич Золотовский
}

Волгоградский государственный университет, г. Волгоград, Российская Федерация 
Аннотация. Введение. В течение ХХ в. под воздействием глобальных социокультурных, политических и экономических процессов функции и сущность музеев претерпели изменения. Одной из наиболее актуальных функций современных музеев является музеефикация. Цель исследования - раскрыть особенности цифровой музеефикации как перспективного направления и актуальной формы музеефикации материальных и нематериальных объектов, входящих в историко-культурное пространство и социокультурную среду. Степень изученности. Предпринятый анализ научной литературы в области музеефикации позволил сделать вывод о том, что имеется достаточная методологическая и фактологическая база для комплексного исследования сущности музеефикации, а также приоритетных аспектов ее организации и развития. Вместе с тем многие проблемы теории и практики музеефикации, в том числе вопрос сущности цифровой музеефикации, не получили даже проблемного определения. Анализ. Особое значение в деятельности по спасению, сохранению, а также введению памятников культурного наследия в современную социокультурную среду приобретает музеефикация. Памятник, являющийся гармоничной частью историкокультурного пространства, не требует искусственной консервации среды или ареала памятника. Определено, что для таких объектов музеефикации обоснованно использовать понятие «динамической музеефикации», наиболее адекватной формой которой следует считать цифровую музеефикацию. Bblводы. Цифровая музеефикация представляется нам как деятельность по трансформации памятников культурного наследия в живые объекты, развивающиеся вместе с их историко-культурным пространством и социокультурной средой. Этот вид практики направлен на обеспечение реализации сохранительных и популяризационных задач с максимальной эффективностью, в рамках формируемой в современных условиях системы «умный город». Цифровая музеефикация объективно делает необходимым создание открытых информационных баз для всех заинтересованных лиц, вне зависимости от правового статуса объекта и субъекта музеефикации. Установленная нами связь пространства памятника культурного наследия с каналами формирования исторической памяти места определяет необходимость организации музеефикации в цифровом креативном городском пространстве.

Ключевые слова: музеефикация, популяризация объектов культурного наследия, объекты культурного наследия, историческая память, креативное пространство.

Цитирование. Золотовский В. А. Цифровая музеефикация как перспективный механизм сохранения и презентации (репрезентации) историко-культурного наследия: к постановке вопроса // Вестник Волгоградского государственного университета. Серия 4, История. Регионоведение. Международные отношения. 2021. - T. 26, № 5. - C. 256-271. - DOI: https://doi.org/10.15688/jvolsu4.2021.5.21

Введение. Постановка проблемы. В течение XX в. под воздействием глобальных социокультурных, политических и экономических процессов функции и сущность музеев претерпели изменения. Институционально они эволюционировали от консервативных, элитарных субъектов коллекционирования к открытым, ориентированным на посетителя общественным институтам, обеспечивающим не только хранение и экспонирование памятников культурного наследия, но и изучение истории культуры.

Следует согласиться с мнением Т.П. Калугиной о том, что происходящие изменения в определенной степени следует понимать как проявление постмодернистского музеефикаторского типа культуры, со свойственным расширением объектов музеефикации в целях публичной демонстрации составных элементов культуры [27]. Именно в этой связи одной из наиболее актуальных функций современных музеев является музеефикация. В самом общем смысле музеефикация означает процесс включения в музейную или схожую по функциям иную, связанную с сохранением и популяризацией социокультурную сферу, материального и нематериального объекта или процесса (его части).

В центре нашего внимания - проблема музеефикации в широком смысле, прежде всего в вопросах субъектов музеефикации, ее форм, видов и направлений. Следует отметить, что основным предметом исследования в рамках данной статьи является вопрос сохранения значения историко-культурных объектов в общественном сознании. Безусловно, изыскание в этом направлении формирует особый интерес к обобщению опыта музеефикации и использования недвижимых памятников культурного наследия в европейской и азиатской практике музейного дела. Прежде всего речь идет об анализе практики и теоретическом осмыслении создания и организации деятельности различных типов музеев под открытым небом [31; 36; 54]. 
Не менее важной представляется проблема музеефикации материальных недвижимых и нематериальных объектов. С точки зрения вопросов сохранения и популяризации культурного наследия представляется актуальным вопрос музеефикации недвижимых памятников материальной культуры, частично отражающих трансформацию социокультурной среды [28; 40;65].

Цель исследования - раскрыть особенности цифровой музеефикации как перспективного направления и актуальной формы музеефикации материальных и нематериальных объектов, входящих в историко-культурное пространство и социокультурную среду. В рамках достижения поставленной цели определены следующие исследовательские задачи: концептуализация музеефикации как форм сохранения культурного наследия; выделение направлений, форм и способов музеефикации; раскрытие специфики использования информационных технологий в музеефикации; определение сущности и выявление перспективных форм цифровой музеефикации.

Степень изученности. Анализ современной литературы позволил выделить основные направления научной мысли в области музеефикации. В частности, отметим особое внимание проблемам специфики практик музеефикации культовых и нематериальных объектов [29, с. 13-105; 51; 63]; характеристике сущности музеефикации мемориальных ландшафтов [37; 44]; раскрытию потенциала музеефикации мест исторических сражений, рассматривается вопрос о необходимости исторической реконструкции $[7 ; 10 ; 15 ; 16]$; отдельным проблемам теории и методики музеефикации [14; 41; 42; 43; 45; 67].

Вместе с тем многие проблемы теории и практики музеефикации не получили даже проблемного определения. В частности, проблема цифровой музеефикации лишь косвенно затрагивалась в современных исследованиях. В большинстве случаев учеными математиками, историками и культурологами рассматривались вопросы использования информационных средств и методов в музеефикации и музейном деле. При этом стоит отметить, что проблема цифровой музеефикации не получила даже общей концептуализации. Так, автор специальной статьи Н.Т. Тарумо- ва ограничила поле собственного исследования лишь систематизацией практики использования цифровых средств в музейном деле, не пытаясь хотя бы в общих суждениях охарактеризовать заявленную в наименовании статьи цифровую музеефикацию [61].

Предпринятый анализ основных направлений научных изысканий в области музеефикации позволил сделать вывод о том, что имеется достаточная методологическая и фактологическая база для комплексного исследования сущности музеефикации, а также приоритетных аспектов ее организации и развития. В этой связи представляется актуальным дальнейшее системное изучение практики музеефикации, выделения ее перспективных форм и методов. При этом необходимо учитывать, что главная задача музеефикации состоит не только в нормативно определенном сохранении историко-культурного наследия и поддержании интереса к изучению собственной истории. В рамках музеефикации культурно-исторического пространства обеспечивается социокультурная идентификация населения [30, с. $10-13 ; 47 ; 52 ; 62 ; 60]$.

Анализ. Музеефикация: основные направления, формы и способы. В настоящее время в России нет единого подхода и системного понимания методики охраны историко-культурного наследия материального и нематериального характера. Наибольшее распространение получила практика создания музейных фондов и музеев-заповедников. Как комплексные объекты музеефикации последние становятся центрами популяризации традиционных промыслов, а посредством исторических реконструкций также и этнокультурных особенностей.

«Живые музеи» также вовлечены в музеефикационную работу с материальным и нематериальным наследием. Представленное в научной литературе понимание сущности этих музеев позволяет их разделить на две группы: живые, или средовые музеи, воплощающие объединение предметно-художественной среды и социально-бытовых объектов; живые музеи, направленные на расширенную интерактивную популяризационную деятельность. Последние, выделяемые в качестве наиболее актуальных [26; 53], как объекты с обширной познавательной составляющей, 
в большей степени соответствуют задачам нематериальной музеефикации. В то время как традиционные музеи в большей степени отвечают задачам сохранения и популяризации историко-культурного наследия в материальной форме.

В современных условиях глобализационного кризиса общества и трансформации экономики памятники материального и нематериального наследия в большей степени находятся под угрозой разрушения. В этой связи особое значение приобретают задачи по спасению, сохранению (консервации), а также актуализации («введению») как включения памятников наследия в современную социокультурную среду посредством музеефикации $[13 ; 29$, c. $70-74,82,99,106-110 ; 41$, c. $139 ; 58$, c. 28-30]. Безусловно, указанные направления деятельности связаны между собой, однако их реализация в конкретных формах музеефикации имеет специфику. Так, например, сохранение памятников культурного наследия обеспечивается соответствующей нормативной базой и институционально передано традиционным музеям. В то время как актуализация не ограничивается конкретными субъектами и может быть более эффективной в рамках деятельности нетрадиционных музеев.

Современные подходы к актуализации, введению и использованию объектов культурно-исторического наследия не способствуют решению приоритетных задач развития культуры. Например, наличие разновременной городской застройки, с одной стороны, требует развития современной городской экономики. С другой - очевидна необходимость сохранения уникальной городской архитектуры. В этой связи следует отметить, что именно средовый подход позволяет конкретным формам музеефикации обеспечить актуализацию и введение культурно-исторических объектов, в том числе в составе комплексов и ансамблей. При этом особого внимания заслуживает анализ практики и теоретическое осмысление создания и организации деятельности различных типов музеев под открытым небом $[13 ; 29$, с. $85-105 ; 35$, с. $254-256 ; 65$, c. $59-60]$.

Полная или частичная музеефикация традиционно связаны с определением соответствующего правового режима и статуса объекта. Отметим, что выделенная в науч- ной литературе как традиционная форма [12, c. $37-38 ; 39$, с. $62-63 ; 31$, с. $12-13 ; 38$, c. $35-$ 37], полная материальная музеефикация является процессом не только капиталоемким, но и ограничивающим потенциал введения / использования объектов культурного наследия. Именно по этой причине огромное количество недвижимых памятников, имеющих историко-культурную ценность, остаются немузеефицированными. Такой подход не учитывает охранительные и популяризационные возможности иных уникальных объектов, формирующих историко-культурную среду.

Понятие музеефикации начал употреблять применительно к теории музейного дела Ф.И. Шмидт. Последующее качественное развитие доктринального понимания и практики музеефикации началось в период масштабных реставрационных работ и общего развития отечественных музеев в 50-60-е гг. XX в. [29, с. 19-20, 43].

В современных условиях в отечественной и зарубежной практике музеефикация развивается в двух основных направлениях. В рамках первого предполагается условное или фактическое изъятие объекта-памятника из естественного ареала с последующей трансформацией в объект показа с учетом его ценности. В отношении недвижимых материальных памятников такая музеефикация предполагает различные методы сохранения - от реставрации до консервации. Отметим, что музеефикация с извлечением объектов из первоначального пространства создания в качестве последствия может иметь полное уничтожение памятника [41, с. 137; 62, с. 27].

Второй вариант предполагает музеефикацию памятников культурного наследия через актуализацию или введение в социокультурную среду. Это направление в том числе реализуется в отношении материальной и нематериальной музеефикации в форме, например, музеев под открытым небом [17; 36; 54]. Прежде всего такой подход относится к определенным видам археологического, этнокультурного и архитектурного наследия.

Вне зависимости от направления и формы телеологическая сущность музеефикации заключается в сохранении исторической содержательной характеристики памятника. При этом музеефикация недвижимых мате- 
риальных объектов позволяет сделать их гармоничной частью социокультурной среды [12, c. $38 ; 42 ; 45]$. Именно музеефикация, а не восстановительные и иные сохранительные работы предполагают выявление памятников, их изучение и последующее введение в музейный и туристский показ, а также актуализацию их смыслов с точки зрения социокультурной среды.

Изменение социокультурной среды обусловливает необходимость обеспечения сохранности исторических пространств, вобравших памятники материальной культуры и хранящих историческую память как часть духовного наследия [11, с. 1-2; 60, с. 145-147]. Актуализация этого направления, в частности, выражается в многочисленных отечественных и зарубежных примерах музеефикации нематериальных объектов в комплексе практики сохранения уникальной культурной среды. Однако, учитывая в качестве основного объекта музеефикации материальные объекты особого статуса, используемые в музеефикационной практике с целью сохранения исторической памяти территории [12, с. $37-$ $38 ; 13$, с. $61-62 ; 50$, с. 70], необходимо отметить важность сохранения всего культурноисторического пространства, включая так называемые периферийные объекты. Нередко именно они являются «местами жизни» населения и становятся опорными точками топоса «малой родины» [12]. В этой связи следует подчеркнуть особое значение в современной повседневной жизни, психическом опыте и языке именно пространственных, а не временных категорий [20, с. 107].

Музеефикация материальных объектов позволяет сохранить памятники как знаки, или символы пространства исторической памяти народа - носителя языка означаемого. Именно в этом случае музеефицированные памятники становятся объектами социокультурной идентификации личности. Популяризация объектов культурного наследия и их сохранение в широком смысле обеспечивают стимулирование и участвуют в формировании чувства личной сопричастности посредством материальной и нематериальной музеефикации. В частности, в форме реконструкции места и истории личности, включающих в себя: сведения о месторасположении объекта, ис- торию его создания и изменения, историю его изучения, историю личностей (общностей), связанных с местом / объектом [12, с. 37-38].

Отметим, что музеефикация археологических объектов и их групп, а также мест исторических сражений является частью деятельности по сохранению и популяризации. Наиболее актуальный вопрос материальной музеефикации таких объектов - определение границ охранной территории с последующей передачей в собственность публичному субъекту музеефикации [22]. После его проведения устанавливается разрешительный режим проведения изысканий культурного слоя с привлечением соответствующих специалистов [32; 33]. Наиболее подходящей формой музеефикации археологических объектов является частичная музеефикация, распространенная в зарубежной практике. Ее сущность заключается в обеспечении популяризации объектов, сохранении исторических памятников посредством установки информационных табличек или знаков, без возведения музеев и (или) материальной передачи объекта субъекту музеефикации с организацией соответствующих охранных, или сохранительных работ. Именно такая деятельность может быть успешно дополнена элементами цифровой музеефикации посредством формирования электронной базы данных об объекте, размещением в свободном доступе в сети Интернет. Такой подход позволяет расширить социокультурный ландшафт и ввести в культурную среду большое количество историко-культурных памятников.

Объекты музеефикации. К объектам музеефикации необходимо относить не только приоритетные объекты музейного интереca (памятники), но и открытое пространство в их окружении. Следует подчеркнуть, что в ряде случаев сам памятник сохраняет свое сущностное значение исключительно в контексте среды, частью которой он является. Поскольку памятник в среде его формирования (создания) представляет собой символ, воплощающий духовную деятельность (в части или целом) конкретного сообщества / общества, конкретного пространства. Таким образом, объектом музеефикации в определенных условиях становится «пространство, создающее системное объединение объектов» [50, с. 75]. 
Такой выбор комплексного объекта музеефикации создает определенные и вполне объективные сложности: традиционно процесс музеефикации, организуемый с целью сохранения объекта, определен нормативно с соответствующими изменениями статуса конкретного объекта, условиями его сохранения и т. д. Вместе с тем пространство вокруг памятника, его ареал, создающий визуальный комплекс, чаще всего относится к меняющейся градостроительной среде.

Возникает закономерный вопрос о том, как зафиксировать меняющееся пространство. Полагаем, что «живой» памятник, являющийся гармоничной частью историко-культурного пространства и социокультурной среды, находящийся в диалоге с обществом, общающийся с ним на одном символическом языке, не требует искусственной консервации среды или ареала памятника. Это может оказать негативное воздействие на восприятие памятника, оторвав его от меняющегося общества и пространства. В этом случае обоснованно использовать понятие «динамической музеефикации». В рамках такого направления музеефикации наиболее адекватной ее формой следует считать именно цифровую музеефикацию, позволяющую фиксировать качественные признаки изменения общества, выраженные в том числе в визуализации пространства $[19$, с. $50-52 ; 28$, с. $128-129 ; 49$, с. 134$]$.

Введенные в цифровую среду и массовую культуру множество объектов культурного наследия зарубежных стран получили у наших соотечественников большую узнаваемость, чем отечественные памятники историко-культурного наследия федерального и регионального значения. Безусловно, на это оказывает влияние современная система образования. Кроме того, очевидна проблема смены или устаревания языка памятника-символа.

В современном технологическом обществе объективно произошла трансформация как самого знания, так и форм его трансляции. Знание становится общедоступным и неустойчивым с точки зрения длительности использования. Это в том числе изменило подход к восприятию объектов музейного показа.

Памятник, как основной объект музеефикации, являющийся знаком конкретной ис- торической памяти, со временем теряет связь с обществом, прежде всего ввиду изменения языка знания. Именно язык был основным каналом «существования» памятника, он делал памятник живым как для ученого субъекта, так и для обывателя. Экскурсовод выступал в этой системе отношений связующим звеном между памятником и лицом, его воспринимающим. В контексте изменения языка культуры, смены или изменений в системе культурных ценностей, язык памятника-знака становится чуждым лицу, воспринимающему памятник. Таким образом, теряется весь смысл памятника-знака, что приводит к разрушению его сущности. В этой ситуации, единственным условием жизни памятника-знака становится выведение (освоение) памятника как объекта музеефикации в социокультурную среду. Такое освоение объекта музеефикации должно осуществляться без использования его собственного языка - канала передачи информации, что позволит памятнику вновь обрести сущность через актуальный язык общности. Именно эта форма жизни объекта музеефикации предусмотрена в рамках развития цифровой музеефикации.

При этом наиболее важным считаем не столько жизнь памятника посредством актуального канала передачи информации, сколько создание условий существования памятника в форме неограниченного временем и пространством освоения в цифровой среде. Цифровая музеефикация позволит обеспечивать реализацию сохранительных и популяризационных задач с максимальной эффективностью в рамках формируемой в современных условиях системы «умный город», объединяющих всех заинтересованных лиц. В этой связи цифровая музеефикация представляется нам как трансформация памятников культурного наследия в живые объекты, развивающиеся вместе с их историко-культурным пространством и социокультурной средой.

Музеефикация выступает в качестве основного направления охранной деятельности в отношении материальных и нематериальных объектов культурного наследия. В самом общем виде музеефикация как процесс представляется в нескольких этапах - в виде введения, актуализации, обеспечения сохранности объекта, поддержания нормального физи- 
ческого состояния, изучения объекта, его презентации / репрезентации и интерпретации.

Традиционное понимание музеефикации, с привлечением исключительно публичных форм регулирования, представляется нам крайне институционализированным и в силу этого ограниченным. Полагаем, что для достижения главной цели музеефикации необходимо расширить круг вовлеченных субъектов. Безусловно, перевод объекта в новый статус в рамках музеефикации должен осуществляться именно музеем, как культурной институцией. Однако наполнение объекта культурного наследия (памятника) сущностным знаковым содержанием и выработка формы трансляции смыслов, составляющих памятник, должны формироваться более широким кругом участников. В качестве таковых должны прежде всего восприниматься носители языка знакапамятника, а также представители естественной для этого памятника социокультурной среды, представители различных отраслей научного исторического знания [11, с. 2-7; 62, с. 27].

Информационные технологии в музеефикации. Новейшие информационно-коммуникационные технологии применяются участниками музеефикации на всех ее этапах, вне зависимости от вида и формы объектов. Уникальность использования информационных технологий как средств и методов музеефикации заключается в их междисциплинарном характере. Синтез технологий и гуманитарного знания позволяет расширить не только сам перечень объектов музеефикации, но и прежде всего их информационно-аналитические характеристики. Собственно музеефикационные технологии как организованный комплекс специальных средств позволяют объединить разнородную информацию об объекте музеефикации в постоянно действующую динамическую структуру.

Расширение возможностей музеефикации видится нам в переходе к цифровому формату, позволяющему не только создать неограниченный канал трансляции историкокультурных смыслов объекта, но и дополнить сам памятник через формат неполной нематериальной музеефикации, цифровое моделирование и историческую реконструкцию, сбор и цифровую систематизацию архивных источников.
Кроме того, следует подчеркнуть, что в процессе музеефикации определенного вида объектов, например, археологических, необходимо учитывать возможности комплексной музеефикации, включающей соответствующие мероприятия не только в отношении конкретного объекта, но и окружающей природной среды. Такой подход применим и в музеефикации объектов городской среды.

Использование информационных технологий в процессе цифровой музеефикации предполагает не только создание информационной источниковой базы, используемой в исследовательских целях, но и разработку объемных изображений музеефицированных памятников. При этом, в зависимости от типа памятника, возможно графическое объединение исторических форм объекта как слоев, а также сопровождение визуального изображения памятника сопутствующим материалом специальный видеоряд, анимационная проекция, музыкальное и текстовое сопровождение. Следует отметить особое место источниковой составляющей задач цифровой музеефикации, подчеркнутое наличием специальных исследований по этой теме [23; 68].

Такая информационная форма цифровой музеефикации позволяет использовать ее в широких популяризационных целях. Кроме того, объемные изображения используются как методы воссоздания утраченной части, или целого музеефицированного объекта [1, c. $31 ; 64]$. В таком случае для реконструкции утраченного объекта применяется методика математического моделирования материальных объектов [1, с. 31-32; 19, с. 50-54].

За последние двадцать лет сложилась общая практика в области применения технологий трехмерного моделирования в исторических и археологических исследованиях. Особое внимание уделялось разработке подходов и методов синтеза источников в использовании программ трехмерного моделирования. Наиболее успешные практики внедрения информационных технологий в музеефикацию реализованы коллективами, объединившими в качестве участников ученых-математиков, обеспечивающих математическое моделирование, а также искусствоведов и историков. Итогом совместной работы таких групп являются не только новые формы презентации 
и репрезентации объектов культурного наследия в рамках нематериальной музеефикации ${ }^{2}$. Они имеют в том числе прикладное значение в проектировании комплекса, или отдельных работ по материальной музеефикации, включая виртуальную и материальную реконструкцию утраченных объектов [4, с. 10; 55].

Использование 3D-моделирования позволяет применять технологии лазерного сканирования с заданными алгоритмами сбора отсканированных фрагментов, направленных на реконструкцию объекта как целого. Аналогичным образом технологии лазерного сканировании с дополнением результатов аэрофотосъемкой позволяют реконструировать не только объекты культурного наследия, но и осуществлять реконструкцию городского пространства с учетом всех исторических изменений $[4$, с. $20-21 ; 5$, с. $54 ; 6 ; 18]$. В ряде случаев именно виртуализация в форме трехмерного моделирования позволила реконструировать городскую застройку, получить перспективы города, использовать визуальный источник, установив места расположения объектов, и т. д. [4, с. 26; 34].

В современной науке выделяют две группы работ по созданию виртуальных реконструкций историко-культурного наследия: академические и научно-популярные $[5 ; 8$, с. $5 ; 46$, c. 51]. Значение академической виртуализации заключается в разработке компьютеризированных объектов культурно-исторического наследия, необходимых для пространственного анализа. Создаваемые междисциплинарными группами виртуальные модели позволяют реконструировать внешний вид объектов, внутренние и внешние архитектурные особенности объектов. Разрабатываемый как историческая реконструкция такой объект может использоваться как полноценный исторический источник.

Кроме научных, трехмерные технологии, безусловно, призваны решать и просветительские задачи, в качестве актуальной формы репрезентации, сохранения и визуализации культурного наследия. В этой связи выделяется следующая методика: а) трехмерная модель, представляющая собой визуально ориентированную базу системно организованного исследовательского материала (визуализация объекта предполагает включение временных периодов эволюции объекта); б) 3D-модели, созданные как реконструкции, направленные на решение задач по репрезентации объектов историко-культурного наследия [2; 19, с. 49-54; 57].

Субъекты цифровой музеефикации. В рамках использования цифровых технологий все участники музеефикации от исследователей и реставраторов до представителей научно-просветительской сферы могут как формировать, так и использовать соответствующую информацию. Музеефикация предполагает комплексное изучение истории памятника, включая все этапы исторического изыскания от формирования библиографии и изучения историографии объекта до проблемного анализа отдельных этапов истории памятника. Сформированная источниковая и историографическая база должна стать основой разработки актуального для конкретного памятника вида цифрового паспорта.

При этом вся разнородная информация о памятнике может быть объединена в общий массив данных, сгруппированных и организованных в форме открытой системы, снабженной рубрикаторами и дополненной соответствующими каналами обновления. Речь идет о создании единой базы, включающей в себя выписки, фото и скан-копии архивных документов, рукописных источников, отчетов, фото- и видеоизображений, историческую изографию и т. д. В качестве модели такой системы можно использовать предложения коллектива авторов, разработавших проект онлайн-презентации результатов виртуальной реконструкции [3]. Кроме того, в определенной степени указанным характеристикам соответствуют действующие в настоящее время информационные базы данных по объектам культурного наследия [59].

В рамках институциональной музеефикации очевидна необходимость открытия информационной базы для ее пополнения прямыми и косвенными публичными участниками музеефикации объекта (от историков, искусствоведов, математиков - разработчиков 3D-модели объекта для репрезентации, или реконструкции, до работников архивов и библиотек, способных дополнить паспорт объекта источниками). Цифровая музеефикация, в том числе в форме нематериальной музеефи- 
кации, объективно делает необходимым создание открытых информационных баз для всех заинтересованных лиц, вне зависимости от правового статуса объекта и субъектов музеефикации.

Основные формы и средства цифровой музеефикации. Цифровая музеефикация, безусловно, должна быть ориентирована на ее реализацию в приоритетной цифровой форме с использованием 3D-моделей объектов культурного наследия. В специальной литературе виртуальные модели музеефицированных объектов, а также памятников в общем, прямо связаны с методом визуализации объекта. Этот метод позволяет не только реконструировать в модели внешние признаки объекта, но и дает возможность раскрыть его качественные характеристики с учетом использования историко-генетического метода ${ }^{3}$.

Таким образом, очевидно, что в настоящее время специалисты в сфере охраны объектов историко-культурного наследия могут использовать действенные инструменты воссоздания не только облика памятников, но и его качественных характеристик, в том числе полностью утраченных.

Внедрение указанных нами форм и средств цифровой музеефикации позволит перейти к широкому внедрению в музейную практику тематических электронных коллекций 3D-моделей объектов культурного наследия и соответствующих информационных баз данных, обеспечивающих возможность проведения комплексного сравнительно-типологического исследования. Вместе с тем следует отметить, что 3D-моделирование как средство, или метод музеефикации может обеспечить сохранность историко-культурного объекта от разрушения, а также даст возможность наиболее эффективно ввести его в социокультурную среду.

Особенно актуально такое применение $3 \mathrm{D}$-технологий в вопросах музеефикации археологических и архитектурных объектов древнего мира и средневекового периода, а также в большинстве случаев несохранившихся в изначальном виде, но имеющих специфический историко-культурный слой, мест сражений. Применение к последним из перечисленных объектов 3D-моделирования как метода музеефикации основано не только на информационно-аналитической базе общего характера, но может быть дополнено проекционным сканированием поверхности [56].

При использовании такой методики музеефикации мест сражений происходит не только визуальное усиление эмоционального восприятия конкретного события, имеющего значение как средства патриотического воспитания и популяризации культурно-исторического наследия. Оно позволяет воссоздать необходимые элементы поля боя, а также более определенно представить ход сражения и движение боевых порядков [69, с. 290].

Описанный спектр применения информационных технологий в музейном деле полностью соответствует направлениям и этапам музеефикационной деятельности. При этом цифровая музеефикация с применением методов объемной цифровой реконструкции (созданию виртуальных моделей) утраченных полностью или частично объектов, безусловно, обеспечивает раскрытие научной, историко-культурной и эстетической ценности памятников. Следовательно, характеризуемые нами информационные методы и средства определенно соответствуют признакам музеефикации памятников как процесса.

Среда цифровой нематериальной музеефикации. Указанная нами связь пространства памятника с каналами формирования исторической памяти места определяет необходимость организации цифровой музеефикации в цифровом креативном городском пространстве с элементами концепции «умный город». Выступая в качестве топоса, организующего и трансформирующего систему социальных отношений, систему ценностей, креативное городское пространство объединяет разнонаправленные явления в виде социокультурного синтеза, стимулирует творческую инициативу, позволяет усилить эмоциональные связи социума с ареалом обитания посредством личного участия в его формировании и трансформации [21, с. 86-88].

Вместе с тем современные формы коммуникации, в наибольшей степени определяющие направленность развития общества, приводят к виртуализации как самого общества, так и социокультурной среды. В таких условиях и происходит актуализация креативного пространства в цифровой форме [48, с. 49]. 
Развивая нематериальную музеефикацию в цифровом креативном пространстве, создаются условия формирования социокультурной среды в интерактивной и не имеющей ограничений форме. Именно так, посредством сохранения и популяризации историко-культурных памятников, обеспечивается личное участие каждого члена общества в формировании единого культурного пространства и преодолении социальной разобщенности. Кроме того, в этих условиях стираются границы между создателями культурного пространства и потребителями соответствующих благ.

Необходимо учитывать, что динамическая виртуализация креативного пространства создает уникальные условия для его открытого развития. Речь также идет о новых социальных и культурных практиках, участники которых формируют и открыто распространяют новые ценности различного, в том числе деструктивного по характеру содержания. В этой связи следует подчеркнуть, что цифровая нематериальная музеефикация как открытая коммуникационная социокультурная практика может быть реализована в таких же разновекторных направлениях.

Результаты. Памятник как объект музеефикации с идеалистической точки зрения обладает общественной ценностью, которая не всегда может быть, а в ряде случаев не должна быть личной или индивидуальной. В современном информационном обществе, развивающемся в визуализируемом канале коммуникации, возникают условия разобщенности ценностей, которые становятся формой индивидуализации и самоопределения личности. В особенности это касается детской и юношеской категорий населения, как наиболее вовлеченных в информационную социокультурную среду, в том числе в креативное цифровое пространство.

В таких условиях возникает угроза нарушения культурно-исторической преемственности и партикуляции исторической памяти. Сами же памятники, исключаясь таким образом из символического диалога с обществом, утрачивают свое значение. Избежать таких негативных последствий можно лишь учитывая, что цифровое креативное пространство, как форма социальной коммуникации и место реализации практики цифровой музеефикации, может быть охарактеризовано четырьмя основными функциями: познавательной (сохранение историко-культурного наследия); рекреационной (организация досуга); политической (формирование пространства политического диалога); социальной (организация взаимодействия между людьми и органами публичного управления) [25, с. 123].

Реализация этих функций возможна лишь при прямом координирующем участии в качестве системообразующего элемента этих отношений конкретного публичного субъекта. В вопросах цифровой нематериальной музеефикации им должен стать региональный орган исполнительной власти, обеспечивающий сохранение, использование и популяризацию объектов культурного наследия, находящихся в собственности региона.

К основным субъектам следует отнести: музеи, архивы, библиотеки, а также экспертные общественные советы при указанных органах власти и представителей научного сообщества. Они должны выступать инициаторами, координаторами и основными участниками, обеспечивающими цифровую музеефикацию.

Вопросы популяризации и развития соответствующих ресурсов, информационно обеспечивающих цифровую музеефикацию, являются приоритетными для остальных субъектов: участники коммерческого сектора услуг в сфере культуры и общественные организации, вовлеченные в деятельность по популяризации культурного наследия, представители конкретной социокультурной среды.

\section{ПРИМЕЧАНИЯ}

${ }^{1}$ Работа выполнена при финансовой поддержке Минобрнауки России в рамках проекта № 06332020-0004 «Развитие методики виртуальной 3D-peконструкции исторических объектов».

The study was financially supported by the Ministry of Science and Higher Education of the Russian Federation as research project no. 0633-2020-0004 "Development of methods of virtual 3D reconstruction of historical objects".

${ }^{2}$ Наиболее конкретными примерами репрезентации являются комбинированные и цифровые экскурсии. Например, см.: [9; 66].

${ }^{3}$ Безусловно, в рамках музеефикации необходимо учитывать широкие возможности виртуа- 
лизации. Так, в ходе моделирования могут быть воспроизведены не только сами объекты, но и исторические процессы (производственные, ритуальные, военные сражения и пр.). Работа над раскрытием специфики моделирования исторических процессов и явлений ведется в России с девяностых годов прошлого века. Исследователи изучали вопросы методов и методологии компьютерного моделирования исторических процессов и явлений [измерительные/отражательные и имитационные (прогностические, контрфактические и альтернативные)] [5; $24 ; 4$, c. 10].

\section{REFERENCES}

1. Anikeeva S.O. Ob opyte ispolzovaniia tekhnologii bim dlia muzeefikatsii dereviannykh pamiatnikov arkhitektury [About the Experience of Using Bim Technology for the Museumification of Wooden Architectural Monuments]. Vestnik Tomskogo gosudarstvennogo universiteta. Kulturologiia $i$ iskusstvovedenie [Bulletin of the Tomsk State University. Cultural Studies and Art History], 2014, vol. 1 (13), pp. 31-36.

2. Baryshev R.A. Virtualnaia istoricheskaia rekonstruktsiia Troitskoi tserkvi g. Eniseiska [Virtual Historical Reconstruction of the Trinity Church of Yeniseisk]. Zhurnal Sibirskogo federalnogo universiteta. Seriia «Gumanitarnye nauki» [Journal of the Siberian Federal University. The Series "Humanities"], 2011, vol. 4, no. 7, pp. 973-983.

3. Borodkin L.I. et al. Reprezentatsiia $i$ vizualizatsiia $\mathrm{v}$ onlaine rezultatov virtualnoi rekonstruktsii [Representation and Visualization of the Results of Virtual Reconstruction Online]. Istoricheskaia informatika. Informatsionnye tekhnologii $i$ matematicheskie metody $v$ istoricheskikh issledovaniiakh [Historical Informatics. Information Technologies and Mathematical Methods in Historical Research], 2015, vol. 3-4 (13-14), pp. 3-18.

4. Borodkin L.I., Zherebiatev D.I. Sovremennye tendentsii $\mathrm{v}$ razrabotke virtualnykh rekonstruktsii obieektov istoriko-kulturnogo naslediia: mezhdunarodnyi opyt [Modern Trends in the Development of Virtual Reconstructions a Historical and Cultural Heritage Objects: International Experience]. Virtualnaia rekonstruktsiia istorikokulturnogo naslediia $v$ formatakh nauchnogo issledovaniia i obrazovatelnogo protsessa [Virtual Reconstruction of Historical and Cultural Heritage in the Formats of Scientific Research and Educational Process. Collection of Scientific Articles]. Krasnoyarsk, Siberian Federal University Publ., 2012, pp. 10-30.

5. Borodkin L.I., Zherebiatev D.I. Tekhnologii 3d-modelirovaniia $\mathrm{v}$ istoricheskikh issledovaniiakh: ot vizualizatsii $\mathrm{k}$ analitike [3D Modeling Technologies in
Historical Research: From Visualization to Analytics]. Istoricheskaia informatika. Informatsionnye tekhnologii i matematicheskie metody vistoricheskikh issledovaniiakh [Historical Informatics. Information Technologies and Mathematical Methods in Historical Research], 2012, vol. 2 (2), pp. 49-63.

6. Bush P.D. Virtualnaia rekonstruktsiia ruinirovannogo obieekta kulturnogo naslediia na primere zamka Brandenburg v Kaliningradskoi oblasti [Virtual Reconstruction of a Ruined Cultural Heritage Object on the Example of Brandenburg Castle in Kaliningrad Region]. Nauka, obrazovanie $i$ eksperimentalnoe proektirovanie. Trudy MARKhI [Science, Education and Experimental Design. The Works of MARKHI]. Moscow, MARKHI Publ., 2016, pp. 413-416.

7. Bush P.D. Memorialnaia konservatsiia i muzeefikatsiia ruin, stavshikh sledstviem voennykh deistvii na territorii Rossiiskoi Federatsii i postsovetskogo prostranstva [Memorial Conservation and Museufication of Ruins that Have Become a Consequence of Military Operations on the Territory of the Russian Federation and the Post-Soviet Space]. Sovremennaia arkhitektura mira [Modern Architecture of the World], 2019, vol. 2 (13), pp. 304-316.

8. Borodkina L.I., Rumiantseva M.V., Barysheva R.A., eds. Virtualnaia rekonstruktsiia istoriko-kulturnogo naslediia $v$ formatakh nauchnogo issledovaniia $i$ obrazovatelnogo protsessa: sb. nauch. st. [Virtual Reconstruction of Historical and Cultural Heritage in the Formats of Scientific Research and Educational Process. Collection of Scientific Articles]. Krasnoyarsk, Siberian Federal University Publ., 2012. 196 p.

9. Virtualnyi muzei [Virtual Museum]. Stalingradskaia bitva [The Battle of Stalingrad]. URL: https://stalingrad-battle.ru/project/ (accessed 22 June 2021).

10. Vlasov V.A. Muzeefikatsiia i memorializatsiia sobytii Velikoi Otechestvennoi Voiny v poslevoennyi period [Museumification and Memorialization of the Events of the Great Patriotic War in the Post-War Period]. Budushchee nauki-2019: sb. nauch. st. 7-i Mezhdunar. molodezh. nauch. konf. [The Future of Science-2019. Collection of Scientific Articles of the $7^{\text {th }}$ International Youth Scientific Conference]. Kursk, South-Western State University, 2019, pp. 67-70.

11. Viazinkin A.Iu., Dvukhzhilova I.V. Problema virtualnykh rekonstruktsii «mest pamiati»v svete prostranstvennogo kulturnogo povorota [The Problem of Virtual Reconstructions of "Places of Memory" in the Light of a Spatial Cultural Turn]. Urbanistika [Urbanistics], 2020, vol. 3, pp. 1-8.

12. Galkina T.V., Rudnitskii Iu.A. Istoricheskaia rekonstruktsiia mesta i lichnosti kak opyt nematerialnoi muzeefikatsii [Historical Reconstruction of a Place and a 
Person As an Experience of Immaterial Museumification]. Vestnik Tomskogo gosudarstvennogo universiteta. Kulturologiia i iskusstvovedenie [Bulletin of the Tomsk State University. Cultural Studies and Art History], 2014, vol. 1 (13), pp. 37-43.

13. Glushkova P.V. Klassifikatsiia muzeev pod otkrytym nebom $\mathrm{v}$ aspekte aktualizatsii nematerialnogo kulturnogonaslediia [Classification of Open-Air Museums in the Aspect of Actualization of Intangible Cultural Heritage]. Vestnik Kemerovskogo gosudarstvennogo universiteta [Bulletin of the Kemerovo State University], 2015, vol. 1-1 (61), pp. 59-63.

14. Golovina S.G. Metody eksponirovaniia i muzeefikatsiia istoricheskikh konstruktsii [Methods of Exhibiting and Museumification of Historical Structures]. Vestnik grazhdanskikh inzhenerov [Bulletin of Civil Engineers], 2021, vol. 1 (84), pp. 5-13.

15. Gorbunov A.V. Muzeefikatsiia polei srazhenii kak obieektov kulturnogo naslediia [Museumification of Battlefields as Objects of Cultural Heritage]. Ekologicheskie problemy muzeev-zapovednikov. Materialy desiatoi vserossiiskoi nauchnoi konferentsii [Ecological Problems of MuseumsReserves. Materials of the $10^{\text {th }}$ All-Russian Scientific Conference], (Moscow, November 15-17, 2005). Moscow, Institute of Heritage Publ., 2008, pp. 52-64.

16. Gorbunov A.V. Sokhranenie istoricheskoi pamiati o Borodinskoi bitve («srazhenii na Moskvereke») na pole srazheniia [Preserving the Historical Memory of the Battle of Borodino ("The Battle on the Moscow River") on the Battlefield]. Srazhenie na Moskve-reke: rossiiskii i frantsuzskii vzgliady spustia dva stoletiia. sbornik materialov rossiiskofrantsuzskogo nauchnogo kollokviuma. Ser. «Trudy istoricheskogo fakulteta $M G U »$ [The Battle on the Moscow River: Russian and French Views After Two Centuries. Collection of Materials of the Russian-French Scientific Colloquium. Series "Proceedings of the Historical Faculty of Moscow State University]. Saint Petersburg, Aleteya Publ., 2019, pp. 237-258.

17. Goroshko N.V., Shmakova G.V. Sovremennye problemy muzeev pod otkrytym nebom i ikh rol $\mathrm{v}$ sokhranenii istoriko-kulturnogo naslediia (na primere sushchestvuiushchikh i perspektivnykh muzeev Novosibirskoi oblasti) [Modern Problems of Open-Air Museums and Their Role in the Preservation of Historical and Cultural Heritage (On the Example of Existing and Promising Museums of Novosibirsk Region)]. Balandinskie chteniia [Balandinsky Readings], 2014, vol. 9, no. 3, pp. 284-287.

18. Granstrem M.A., Zolotareva M.V. Muzeefikatsiia kak politika sokhraneniia obieemnoprostranstvennoi identichnosti fragmentov istoricheskogo goroda [Museumification As a Policy of Preserving the Spatial Identity of Fragments of a Historical City]. Velikie reki'2016. Trudy nauchnogo kongressa [Great Rivers' 2016. Proceedings of the Scientific Congress], 2016, pp. 143-146.

19. Dashkovskaia O.D. Matematicheskoe modelirovanie $\mathrm{v}$ istoricheskikh issledovaniiakh: zadachi, osobennosti i vozmozhnosti primeneniia metoda [Mathematical Modeling in Historical Research: Tasks, Features and Possibilities of Using the Method]. Vestnik Iaroslavskogo gosudarstvennogo universiteta im. P.G. Demidova. Seriia «Gumanitarnye nauki» [Bulletin of the Yaroslavl State University Named After P.G. Demidov. The Humanities Series], 2020, vol. 2 (52), pp. 48-55.

20. Dzheimison F. Postmodernizm, ili Kulturnaia logika pozdnego [Postmodernism, or the Cultural Logic of the Late]. Moscow, Publishing house of the Gaidar Institute, 2019. 808 p.

21. Ermakova L.I., Sukhovskaia D.N. Rol kreativnoi sredy rossiiskogo goroda $\mathrm{v}$ formirovanii tsennostnykh orientatsii lichnosti gorozhanina [The Role of the Creative Environment of the Russian City in the Formation of Value Orientations of a Citizen's Personality]. Istoricheskie, filosofskie, politicheskie $i$ iuridicheskie nauki, kulturologiia i iskusstvovedenie. Voprosy teorii i praktiki [Historical, Philosophical, Political and Legal Sciences, Cultural Studies and Art Criticism. Questions of Theory and Practice], 2016, no. 10 (72), pp. 86-89.

22. Efremova E.V. Muzeefikatsiia obieektov arkheologicheskogo naslediia v svete sovremennogo rossiiskogo zakonodatelstva [Museumification of Archaeological Heritage Objects in the Light of Modern Russian Legislation]. Vestnik Tomskogo gosudarstvennogo universiteta [Bulletin of the Tomsk State University], 2014, vol. 387, pp. 84-90.

23. Zherebiatev D.I. Postroenie otkrytoi informatsionnoi sredyv zadachakh 3d-modelirovaniia: istoriko-kulturnogo naslediia: onlain dostup $\mathrm{k}$ istochnikam virtualnoi rekonstruktsii monastyrskogo kompleksa nachala XX v. [Building an Open Information Environment in 3D Modeling Tasks: Historical and Cultural Heritage: Online Access to Sources of Virtual Reconstruction of the Monastery Complex of the Early $20^{\text {th }}$ Century]. Istoricheskaia informatika. Informatsionnye tekhnologii $i$ matematicheskie metody $v$ istoricheskikh issledovaniiak [Historical Informatics. Information Technologies and Mathematical Methods in Historical Research], 2012, vol. 1 (1), pp. 80-91.

24. Zherebiatev D.I., Konchakov R.B. Tekhnologii trekhmernogo modelirovaniia $\mathrm{v}$ rakurse istoricheskoi informatiki [Technologies of Three-Dimensional Modeling in the Perspective of Historical Informatics]. Krug idei: modeli i tekhnologii istoricheskikh rekonstruktsii. Ser. «Krug idei» [Circle of Ideas: Models and Technologies of Historical Reconstructions. Series “Circle of Ideas"], 2010, pp. 145-174. 
25. Zakharova E.E. Obshchestvennye prostranstva kak faktory sotsiokulturnogo razvitiia lokalnykh territorii [Public Spaces As Factors of Socio-Cultural Development of Local Territories]. Vestnik kultury $i$ iskusstv [Bulletin ofCulture and Arts], 2017, vol. 2 (50), pp. 122-127.

26. Zakhvatova D.S. Poniatie «zhivye muzei» v sovremennoi muzeologii [The Concept of "Living Museums" in Modern Museology]. Lomonosovskie chteniia na Altae: fundamentalnye problemy nauki $i$ obrazovaniia [Lomonosov Readings in the Altai: Fundamental Problems of Science and Education], Barnaul, Altai State University Publ., pp. 3717-3719.

27. Kalugina T.P. Muzei $i$ «muzeefikatorskii» tip kultury [The Museum and the "Museum-Specific" Type of Culture]. URL: http://anthropology.ru/ru/text/ kalugina-tp/muzey-i-muzeefikatorskiy-tip-kultury (accessed 18 June 2021).

28. Kalnitskaia E.Ia. Novye puti muzeefikatsii pamiatnika arkhitektury: Mikhailovskii zamok [New Ways of Museumification of an Architectural Monument]. Izvestiia Rossiiskogo gosudarstvennogo pedagogicheskogo universiteta im. A.I. Gertsena [Proceedings of the A.I. Herzen Russian State Pedagogical University], 2008, vol. 75, pp. 123-131.

29. Kaulen M.E. Muzeefikatsiia istorikokulturnogo naslediia Rossii [Museumification of the Historical and Cultural Heritage of Russia]. Moscow, Eterna Publ., 2012. 432 p.

30. Kaulen M.E. Sredovoi muzei v prostranstve goroda [The Environmental Museum in the Space of the City]. Molodezh i sotsium [Youth and Society], 2012, vol. 5, pp. 9-18.

31. Kaulen M.E. Muzei pod otkrytym nebom: mnogoobrazie modelei i problemy vybora [Open-Air Museums: A Variety of Models and Problems of Choice]. Muzei-zapovedniki muzei budushchego: mat-ly Mezhdunar. nauchn.-praktich. konf., 1822 noiab. 2015 [Museums-Reserves Museums of the Future: Materials of the International Scientific Research. Practical Conference, November 18-22, 2015]. Yelabuga, LLC “ElTIK” Publ., 2015, pp. 11-34.

32. Kepin D.V., Titova E.N. Muzeefikatsiia arkhitekturno-arkheologicheskikh pamiatnikov [Museumification of Architectural and Archaeological Monuments]. Uchenye zapiski muzeia-zapovednika "Tomskaia Pisanitsa» [Scientific Notes of the Museum-Reserve "Tomsk Pisanitsa"], 2018, vol. 8, pp. 112-120.

33. Kovalev D.D., Romanov V.V. Muzeefikatsiia obieektov arkheologicheskogo naslediia (pamiatnikov arkheologii) v Rossiiskoi Federatsii: sovremennye tendentsii, problemy, perspektivy [Museumification of Archaeological Heritage Objects (Archaeological Monuments) in the Russian Federation: Current Trends, Problems, Prospects]. Sovremennoe sostoianie infosfery uchrezhdenii kultury. Materialy
I Mezhdunarodnogo studencheskogo nauchnoprakticheskogo foruma [The Current State of the Infosphere of Cultural Institutions. Proceedings of the $1^{\text {st }}$ International Student Scientific and Practical Forum]. Orel, Orel State Institute of Culture, 2018, pp. 55-59.

34. Konchakov R.B. Primenenie metodiki trekhmernogo prostranstvennogo analiza dlia izucheniia formirovaniia gorodskoi zastroiki i vosstanovleniia kulturnogo naslediia [Application of the Three-Dimensional Spatial Analysis Methodology for Studying the Formation of Urban Development and the Restoration of Cultural Heritage]. Krug idei: metody i tekhnologii istoricheskikh rekonstruktsii: trudy XI konf. Assotsiatsii "Istoriia i kompiuter» [Circle of Ideas: Methods and Technologies of Historical Reconstructions. Proceedings of the $11^{\text {th }}$ Conference of the "History and Computer" Association]. Moscow, Barnaul, Tomsk, MSU Publishing House, 2010, pp. 218-237.

35. Krasilnikova E.E. et al. Muzeefikatsiia gorodskikh territorii kak faktor gradostroitelnogo razvitiia (na primere Volgograda) [Museumification of Urban Territories As a Factor of Urban Development (On the Example of Volgograd)]. Vestnik Volgogradskogo gosudarstvennogo arkhitekturnostroitelnogo universiteta. Seriia: Stroitelstvo $i$ arkhitektura [Bulletin of the Volgograd State University of Architecture and Civil Engineering. Series: Construction and Architecture], 2019, vol. 2 (75), pp. 254-262.

36. Levitskaia E.A., Galdilov G.D. Muzei pod otkrytym nebom kak variant konservatsii pamiatnikov istorii i kultury (na primere ostrova Sakhalin) [Museums Under the Open Sky As a Variant of the Preservation of Monuments of History and Culture (On the Example of the Island of Sakhalin)]. Turizm i muzei: sinergeticheskii effekt vzaimodeistviia [Tourism and Museums: Synergistic Interaction]. Moscow, Publishing House “Znanie-M", 2020, pp. 254-263.

37. Martynov A.I. Muzeefikatsiia pamiatnikov istoriko-kulturnogo naslediia i istoricheskikh mest problema natsionalnaia [Museumification of Monuments of Historical and Cultural Heritage and Historical Places - A National Problem]. Severnyi arkheologicheskii kongress: tez. dokl. [Northern Archaeological Congress. Abstracts of Reports]. Khanty-Mansiysk, Charoid Publishing House, 2006, vol. II, pp. 278-279.

38. Martynov A.I. Osobennosti i problemy muzeefikatsii kulturno-istoricheskogo naslediia Rossii [Features and Problems of Museumification of the Cultural and Historical Heritage of Russia]. Muzeizapovedniki - muzei budushchego: materyaly Mezhdunar. nauch.-prakt. konf., 18-22 noiab. 2015 [Museums-Reserves-Museums of the Future: Materials of International Scientific Research. Practical 
Conference, November 18-22, 2015]. Elabuga, 2015, pp. 35-44.

39. Martynov A.I., Abrosimova Iu.A. Problemy muzeefikatsii materialnogo istoriko-kulturnogo naslediia selskikh territorii Sibiri [Museumification Problems of the Material Historical and Cultural Heritage of Siberia Rural Territories]. Vestnik KemGUKI [Vestnik KemGUKI], 2017, vol. 40, pp. 62-66.

40. Mastenitsa E.N. Kulturnyi landshaft kak obieekt naslediia: podkhody k izucheniiu i problemy sokhraneniia $\mathrm{v}$ muzeiakh pod otkrytym nebom [Cultural Landscape As a Heritage Object: Approaches to the Study and Problems of Preservation in Open-Air Museums]. Vestnik Tomskogo gosudarstvennogo universiteta. Kulturologiia i iskusstvovedenie [Bulletin of the Tomsk State University. Cultural Studies and Art History], 2015, vol. 2 (18), pp. 42-51.

41. Mastenitsa E.N. Muzeefikatsiia gorodskoi sredy: podkhody i metody [Museumification of the Urban Environment: Approaches and Methods]. Istoricheskie, filosofskie, politicheskie i iuridicheskie nauki, kulturologiia i iskusstvovedenie. Voprosy teorii i praktiki [Historical, Philosophical, Political and Legal Sciences, Cultural Studies and Art Criticism. Questions of Theory and Practice]. Tambov, Gramota Publishing House, 2013, vol. 10-1 (36), pp. 137-141.

42. Mastenitsa E.N. Muzei gorodskoi sredy: istoki i sovremennost [The Museum of the Urban Environment: Origins and Modernity]. Kulturologicheskie issledovaniia v Sibiri [Cultural Studies in Siberia], 2009, vol. 27, pp. 148-154.

43. MikhalevaK.A. Formirovaniemetodologicheskikh osnov muzeefikatsii pamiatnikov arkhitektury $\mathrm{v}$ usloviiakh razvitiia istoricheskogo goroda [Formation of Methodological Foundations of Museumification the Architectural Monuments in the Conditions of the Development of a Historical City]. Kazanskaia nauka [Kazan Science], 2014, vol. 9, pp. 28-33.

44. Nikitina N.A. Muzeefikatsiia literaturnomemorialnykh usadebnykh kompleksov: Dis. ... kand. kulturologii [Museumification of Literary and Memorial Estate Complexes. Cand. cult. sci. diss.]. Saint Petersburg, 2005. 186 p.

45. Nikonova A.A. Muzeefikatsiia gorodskoi sredy [Museumification of the Urban Environment]. Sbornik metodicheskikh materialov po proektu «Nulevaia versta» [Collection of Methodological Materials on the Project "Zero Verst"]. Saint Petersburg, Federal State University "CMS named after A.S. Popov", 2010, pp. 35-41.

46. Nikonova A.A. Vizualnye tekhnologii i sokhranenie kulturnogo naslediia Rossii [Visual Technologies and Preservation of the Cultural Heritage of Russia]. Vestnik Sankt-Peterburgskogo gosudarstvennogo universiteta kultury $i$ iskusstv
[Bulletin of the Saint Petersburg State University of Culture and Arts], 2014, vol. 1 (18), pp. 49-53.

47. Nikonova A.A. Rol muzeia $v$ formirovanii kulturnoi identichnosti [The Role of the Museum in the Formation of Cultural Identity]. Voprosy muzeologii [Questions of Museology]. Saint Petersburg, Saint Petersburg State University, Publ., 2010, no. 2 (2), pp. 119-123.

48. Ovcharenko G.V. Evoliutsiia prakticheskikh i teoreticheskikh aspektov upravleniia sotsialnymi innovatsiiami [Evolution of Practical and Theoretical Aspects of Social Innovation Management]. TerraEconomicus, 2012, vol. 10, iss. 1-2, pp. 47-49.

49. Petrova Iu.A. Virtualnyi muzei kak effektivnyi instrument sokhraneniia kulturnogo naslediia i razvitiia muzeinykh sistem [Virtual Museum As an Effective Tool for Preserving Cultural Heritage and Developing Museum Systems]. Vestnik Sankt-Peterburgskogo universiteta. Seriia 6. Filosofiia. Kulturologiia. Politologiia. Pravo. Mezhdunarodnye otnosheniia [Bulletin of the Saint Petersburg University. Series 6. Philosophy. Cultural Studies. Political Science. Right. International Relations], 2012, vol. 3, pp. 132-138.

50. Petrov-Spiridonov N.A. K voprosu muzeefikatsii istoricheski znachimykh arkhitekturnolandshaftnykh territorii evropeiskoi chasti Rossii, vkliuchaiushchikh monastyri i khramy [To the Question of the Museumification of Historically Significant Architectural Territories in the European Part of Russia, Including Monasteries and Temples]. Zhizn Zemli [Life of the Earth], 2016, vol. 38, iss. 1, pp. 68-79.

51. Pimenova K.V. Sakralnye predmety i transformatsii muzeinoi etiki: istoki, problemy, resheniia [Sacred Objects and the Transformation of Museum Ethics: Sources, Problems, Solutions]. Novye issledovaniia Tuvy [The New Research of Tuva], 2019, vol. 2, pp. 115-127.

52. Popova N.A. Muzeefikatsiia kak kontseptsiia sokhraneniia istoriko-kulturnogo naslediia [Museumification As a Concept of Preserving Historical and Cultural Heritage]. Aktualnye voprosy okhrany $i$ ispolzovaniia kulturnogo naslediia Kryma: materialy VI Vserossiiskoi nauchno-prakticheskoi konferentsii, Evpatoriia, 30-31 maia 2019 g. [Topical Issues of Protection and Use of the Cultural Heritage of the Crimea: Materials of the $6^{\text {th }}$ All-Russian Scientific and Practical Conference. Yevpatoria, May 30-31, 2019]. Simferopol, IT «ARIAL» Publ., 2019, pp. 209-214.

53. Prokudina D.A. Nematerialnoe kulturnoe nasledie kak resurs dlia razvitiia territorii [Intangible Cultural Heritage As a Resource for the Development of the Territory]. Kultura i obrazovanie [Culture and Education]. Moscow, Moscow State Institute of Culture Publ., 2020, no. 4(39), pp. 23-31.

54. Rakitianskaia E.V. Muzei pod otkrytym nebom: istoriia i sovremennost [Open-Air Museums: History 
and Modernity]. Zhurnal nauchnykh i prikladnykh issledovanii [Journal of Scientific and Applied Research], 2016, vol. 7, pp. 79-82.

55. Romanova I.A., Poluboiarova N.M. Virtualnaia rekonstruktsiia pamiatnikov istoriko-kulturnogo naslediia Vodianskogo gorodishcha [Virtual Reconstruction of Historical Monuments and Cultural Heritage of the Vodyansky Settlement]. Nauchnaia vizualizatsiia [Scientific Visualization], 2021, vol. 13, no. 3, pp. 9-21.

56. Rumiantsev M.V. et al. Virtualnaia rekonstruktsiia obieektov istoriko-kulturnogo naslediia [Virtual Reconstruction of Historical Objects and Cultural Heritage]. Prikladnaia informatika [Applied Informatics], 2011, vol. 6(36), pp. 62-77.

57. Rumiantsev M.V. Vserossiiskii nauchnometodicheskii seminar «Virtualnaia rekonstruktsiia v formatakh nauchnogo issledovaniia i uchebnogo protsessa» [All-Russian Scientific and Methodological Seminar "Virtual Reconstruction in the Formats of Scientific Research and Educational Process"]. Zhurnal Sibirskogo federalnogo universiteta [Journal of the Siberian Federal University], 2011, vol. 7, iss. 4, pp. 1039-1044.

58. Sartakova A.V. Aktualizatsiia istorikokulturnogo naslediia v muzeinykh institutsiiakh osobo okhraniaemykh prirodnykh territorii Baikalskogo regiona [Actualization of Historical and Cultural Heritage in Museum Institutions of Specially Protected Natural Territories of the Baikal Region]. Nasledie vekov [Heritage of Centuries], 2019, vol. 4(20), pp. 28-34.

59. Svedeniia iz Edinogo gosudarstvennogo reestra obieektov kulturnogo naslediia (pamiatnikov istorii $i$ kultury) narodov Rossiiskoi Federatsii [Information from the Unified State Register of Cultural Heritage Objects (Historical and Cultural Monuments) of the Peoples of the Russian Federation]. URL: https:// opendata.mkrf.ru/opendata/7705851331-egrkn (accessed 22 June 2021).

60. Solovev A.V. Muzeefikatsiia istorii: individualnaia i kollektivnaia pamiat $\mathrm{v}$ kontekste kachestva zhizni [Museumification of History: Individual and Collective Memory in the Context of Quality of Life]. Kachestvo zhizni $v$ fokuse mezhdistsiplinarnykh issledovanii: materialy Natsionalnoi nauchno-prakticheskoi konferentsii s mezhdunarodnym uchastiem. IX Riazanskie sotsiologicheskie chteniia [Quality of Life in the Focus of Interdisciplinary Research. Proceedings of the National Scientific and Practical Conference with International Participation. The $9^{\text {th }}$ Ryazan Sociological Readings]. Moscow, Ippolitov Publishing House, LLC, 2019, pp. 145-153.

61. Tarumova N.T. Tsifrovaia muzeefikatsiia [Digital Museumification]. Sbornik nauchnykh statei $X I X$ Obieedinennoi konferentsii "Internet $i$ sovremennoe obshchestvo»IMS-2016 [Collection of Scientific Articles of the $19^{\text {th }}$ Joint Conference "Internet and Modern Society" IMS-2016. Saint Petersburg, June 22-24, 2016]. Saint Petersburg, 2016, pp. 130-139.

62. Timofeev M.Iu. Muzeefikatsiia SSSR [Museumification of USSR]. Labirint. Zhurnal sotsialno-gumanitarnykh issledovanii [Labyrinth. Journal of Social and Humanitarian Studies], 2014, vol. 5, pp. 25-33.

63. Tokarev A.V., Iashaeva T.Iu. Muzeefikatsiia zagorodnykh peshchernykh monastyrei vizantiiskogo Khersona [Museumification of Suburban Cave Monasteries of Byzantine Kherson]. Izuchenie $i$ sokhranenie drevnikh sakralnykh prostranstv $v$ sovremennom mire (k 1365-letiiu ssylki papy Martina v Khersones): materialy Mezhdunar. nauch. konf. [Study and Preservation of Ancient Sacred Spaces in the Modern World (To the 1365 Anniversary of the Exile of Pope Martin to Chersonesos). Proceedings of the International Scientific Conference]. Simferopol, LLC “Antikva”, 2020, pp. 86-89.

64. Truevtseva O.N. Multimediinaia muzeefikatsiia obieektov kulturnogo naslediia [Multimedia Museumification of Cultural Heritage Objects]. Sovremennye tendentsii $v$ razvitii muzeev $i$ muzeevedeniia: materialy IV Vseros. (s mezhdunar. uchastiem) nauch.-prakt. konf. (Novosibirsk, 2223 okt. 2020 g.) [Modern Trends in the Development of Museums and Museology. Materials of the $4^{\text {th }}$ AllRussian (With International Participation) Scientific and Practical Conference (Novosibirsk, October 2223, 2020)]. Novosibirsk, IPTs NGU, 2020, pp. 76-82.

65. Tsvetnov V.A. O sokhranenii istorikokulturnoi sredy: muzeefikatsiia ili "Zhivoe nasledie" [On the Preservation of the Historical and Cultural Environment: Museumification or "Living Heritage"]. Nauka, obrazovanie $i$ eksperimentalnoe proektirovanie. Trudy MARKhI: materialy Mezhdunar. nauch.-prakt. konf.: sb. st. [Science, Education and Experimental Design. The Works of MARKHI. Proceedings of the International Scientific and Practical Conference. Collection of Articles]. Moscow, MARKHI, 2018, pp. 59-62.

66. Ekspozitsii i vystavki [Expositions and Exhibitions]. GIAMZ Khersones Tavricheskii [GIAMZ Chersonesos Tavrichesky]. URL: https://chersonesossev.ru (accessed 22 June 2021).

67. Iudin M.O. Metody muzeefikatsii obieektov arkhitekturnogo naslediia Kemerovskoi oblasti [Methods of Museumification of Architectural Heritage Objects of the Kemerovo Region]. $V$ mire nauki $i$ iskusstva: voprosy filologii, iskusstvovedeniia $i$ kulturologii [In the World of Science and Art: Questions of Philology, Art History and Cultural Studies], 2016, vol. 12 (67), pp. 59-65. 
68. Iumasheva Iu.Iu. Istochnikovaia baza virtualnykh istoricheskikh rekonstruktsii obieektov istoriko-kulturnogo naslediia: $\mathrm{k}$ postanovke problemy [The Source Base of Virtual Historical Reconstructions of Objects of Historical and Cultural Heritage: Towards the Formulation of the Problem]. Istoricheskaia informatika. Informatsionnye tekhnologii $i$ matematicheskie metody $v$ istoricheskikh issledovaniiakh [Historical Computer Science.
Information Technologies and Mathematical Methods in Historical Research], 2020, vol. 3, pp. 21-50.

69. Iakusheva O.V. Voprosy muzeefikatsii mest istoricheskikh srazhenii [Questions of Museumification of Historical Battles Places]. Vestnik RGGU. Seriia: Filosofiia. Sotsiologiia. Iskusstvovedenie [Bulletin of the Russian State University. Series: Philosophy. Sociology. Art History], 2010, vol. 15 (58), pp. 288-295.

\section{Information About the Author}

Vladimir A. Zolotovskiy, Candidate of Sciences (History), Head of the Department of Service and Tourism, Volgograd State University, Prosp. Universitetsky, 100, 400062 Volgograd, Russian Federation, zolotovskiy.azi@volsu.ru,https://orcid.org/0000-0002-4259-8851

\section{Информация об авторе}

Владимир Алексеевич Золотовский, кандидат исторических наук, заведующий кафедрой сервиса и туризма, Волгоградский государственный университет, просп. Университетский, 100, 400062 г. Волгоград, Российская Федерация, zolotovskiy.azi@volsu.ru, https://orcid.org/0000-0002-4259-8851 